\title{
Study of new developments in birch reduction process and their applications for the synthesis and CNS depressant activity of 3- aminocyclohexa-1,4-diene-1-carboxylic acid and 3-[5-substituted 1,3,4-thiadiazole-2-yl]-2-styryl 5,8-dihydroquinazoline-4 (3H)-ones
}

\author{
Charbe N.B. ${ }^{1 *}$, Mehere A.P. ${ }^{2}$, Shende S.G. ${ }^{3}$, Mohod V.S. ${ }^{4}$, Gautam D.T. ${ }^{4}$, Madusudhan M. ${ }^{5}$ and \\ Chaitanya $\mathrm{Ch}^{6}$ \\ ${ }^{1 *}$ Nalla Narshima Reddy Education Society Group of Institutions School of Pharmacy, Chowdariguda, Via \\ Narapally, Dist - R.R., AP, 500 088, nitincharbe10@yahoo.com, 9052299798 \\ ${ }^{2}$ Sharad Pawar College of Pharmacy, Wanadongri Hingna Road, Nagpur, Maharashtra, 440001 \\ ${ }^{3}$ T.V.E.S Loksewak Madhukarao Chaudhari's College of Pharmacy, Faizpur, Jalgaon, Maharashtra. \\ ${ }^{4}$ K.Y.D.S.C.T's College of Pharmacy, Sakegaon, Bhushawal, Maharashtra, 425201. \\ ${ }^{5}$ Production Department, Bivis Ltd, Choutuppal, R.R District, A.P. \\ ${ }^{6}$ Mother Teresa College of Pharmacy, Ghatkeser, Hyderabad, AP
}

\begin{abstract}
Meta nitro benzoic acid has been reduced to 3-aminocyclohexa-1,5-diene-1-carboxylic acid with three different Birch like reduction condition (Method I, II, III) to 3-aminocyclohexa-1,4-diene-1-carboxylic acid. 3-aminocyclohexa-1,4-diene-1-carboxylic acid is found to be structurally more super impossible on gama-amino butyric acid (GABA) and hence the synthesized compounds was tested for the CNS depressant and muscle relaxant activities. A series of new 3-[5-substituted phenyl-1,3,4-thiadiazole-2-yl]-2styryl 5,8-dihydroquinazoline-4 (3H)-ones were synthesized and evaluated for anticonvulsant, sedativehypnotic and CNS depression activities. Various derivatives of 3-[5-substituted phenyl-1,3,4-thiadiazole-2yl]-2-styryl 5,8-dihydroquinazoline-4 (3H)-ones were examined in the maximal electroshock (MES) induced seizures and subcutaneous pentylenetetrazole (scPTZ) induced seizure models in mice. Rotorod method was employed to determine the neurotoxicity. Out of 9 compounds only 3 compounds showed anticonvulsant activity in one or more test models. All except compound (a) exhibited significant sedativehypnotic activity via actophotometer screen. Forced swim pool method to determine CNS depressant activity resulted in some potent compounds. It can be concluded that synthesized compounds exhibited better sedative-hypnotic and CNS depressant activities than anticonvulsant activity.
\end{abstract}

\section{Introduction}

The Birch reduction has been a synthetically useful and powerful method for the partial reduction of aromatic and heteroaromatic rings for more than 60 years [1]. Numerous compounds have been subjected to reducing conditions that include alkali metal and ammonia with various modifications extensions and development of the Birch reduction [2]. The scope of the Birch reduction covers a variety of aromatic and heteroaromatic systems such as pyridines, indoles, furans and thiophenes [3]. Recently, we have been concerned with the reduction of organic compounds by various methods, which resembles to Birch reduction in terms of mechanism. Methods like use of Hydroxyl ions as an electron source in the presence of Ultra Violet light [4], THF (no ammonia) with lithium metal and catalytic amounts of naphthalene used as an electron source[5,6]. Indigenously developed method like use of ammonia gas instead of Liquid Ammonia with Methanol (Dried) can be satisfactorily useful for the reduction of aromatic compounds with varied yields. In the preceding paper we described three different Birch reduction processes for the reduction of Meta nitro benzoic acid by maintaining different Birch like conditions (Method I, II, III). We also have reduced anthranillic acid to 2-aminocyclohexa-1,4-diene- 1-carboxylic acid which is then converted into 3[5-substituted 1,3,4-thiadiazole-2-yl]-2-styryl 5,8dihydroquinazoline-4 $(3 \mathrm{H})$-ones which were then tested for Anticonvulsant activity, Behavioral and CNS studies. Attempts have not been made to reduce the Meta nitro benzoic acid till date by birch reduction. It can be hypothesized that after the reduction of the compound Meta nitro benzoic acid, the chemical moieties so obtained may have GABA agonist or antagonistic activities. Superimposibility of 3-aminocyclohexa-1,4-diene1-carboxylic acid on GABA has promoted us to select compound Meta nitro benzoic acid for birch reduction by three different methods (I, II, III). Other most frequently and important encountered heterocycles in medicinal chemistry is quinazoline with wide applications including anticonvulsant, sedative, tranquilizer, analgesic, antimicrobial, anesthetic, anticancer, antihypertensive, antiinflammatory, diuretic and muscle relaxant properties [7-9]. Literature survey revealed that the presence of substituted aromatic ring at position 3 and methyl group at position 2 are necessary requirement for the central nervous system (CNS) depression and anticonvulsant activities. In spite of the fact that literally hundreds of quinazolinones related to 2methyl- 3-o-tolyl-4(3H)-quinazolinone (methaqualone) have been synthesized and 
tested for central nervous system (CNS) depression and anticonvulsant activities, none of the drugs currently in use contain the $4(3 \mathrm{H})$ quinazolinone ring system. With this previous literature survey we tried to synthesis various analogous of 2-methyl-5,8-dihydroquinazolin$4(3 H)$-one [10]. Among the few reports in the literature our attention was drawn to the earlier discovery by Boltze et al. [11] andWolfe et al. [12] that modification of methyl group by some other chemical moiety yielded structural analogues with anticonvulsant activity. Medicinal chemists over the years have substituted different heterocyclic rings at position 3 of the $4(3 \mathrm{H})$-quinazolinone to get potent CNS acting drugs. 1,3,4-Thiadiazoles nucleus itself exhibits anticonvulsant, sedativehypnotic and CNS neurotoxicity activities [13]. In hope of getting synergistic response of $4(3 \mathrm{H})$ quinazolinone nucleus itself, substitution of 1,3,4thiadiazoles nucleus at third position and chemically modifying second position of $4(3 \mathrm{H})$ dihydroquinazolinone, the present paper reports on the synthesis, anticonvulsant, neurotoxicity, CNS depressant activity and behavioral study of 9 new 3-(1-3-4-thiadiazol-2-yl)- 2-styryl 5,8dihydroquinazoline-4 $(3 \mathrm{H})$-ones.

\section{Experimental}

All the chemicals used in the synthesis were of analytical grade, procured from E-Merck (India) Limited, Mumbai; Loba Chemie Pvt.Ltd., Mumbai; S.D. Fine-Chem,Ltd.,Mumbai; Burgoynes and Co., Bombay; Thomas Baker(Chemicals) Ltd, Mumbai; Himedia Laboratories Pvt.Limited, Mumbai and were used without further purification. The solvents used were of spectroscopic grade. The elementary analysis was performed at University Department of Pharmaceutical Sciences; RTM University of Nagpur, Nagpur, India. Elementary analyses for $\mathrm{C}, \mathrm{H}, \mathrm{N}$ were within $\pm 0.4 \%$ of theoretical values. The visible absorption spectrum was obtained on Shimadzu 1601 spectrophotometer. IR spectrum was recorded using $\mathrm{KBr}$ pellets on FTIR-Vector 22, Bruker, France spectrophotometer at Indian Bureau of Mines, Nagpur. ${ }^{1} \mathrm{H}$ NMR spectrum was taken on a Varian EM 390 spectrophotometer at Department of Chemistry, University of Pune, Pune, India. GCMS spectrum of the compound was recorded using DMSO as solvent on Shimazdu GCMA QP-2010 at Department of Chemistry, Institute of Science, Mumbai. The melting point of synthesized dye was determined by Veego's Precision Melting Point apparatus. The purity and homogeneity of compound was checked using thin layer chromatography technique.

\section{Reduction of $\boldsymbol{m}$-nitrobenzoic acid by ammonia} gas method (Method I)

In a three neck round bottom flask which was equipped with pressure equalizing funnel, $6.2 \mathrm{~g}$ of sodium metal was added in $100 \mathrm{ml}$ of dry ethanol and flask was kept in the cooling mixture of crystalline calcium chloride and crust ice [14](practical vogal). Ammonia solution was heated on the heating mental at temp of $30^{\circ} \mathrm{C}$ to liberate the ammonia gas. The ammonia gas was then allowed to pass through the calcium chloride (Fused) guard tube to remove the moisture ammonia gas was then bubbled in the mixture of dry ethanol and sodium metal for $3 \mathrm{hr}$. A solution of $10 \mathrm{~g}$ of m-nitrobenzoic acid in $50 \mathrm{ml}$ of dry ethanol was then added slowely from the pressure-equalizing funnel followed by $14.6 \mathrm{~g}$ of ammonium chloride. In three neck round bottom flask ammonia gas was continuously passed through mixture for $4 \mathrm{hr}$. Ammonia was then evaporated and the residual material was dissolved in ice $(500 \mathrm{ml})$. After acidification with $10 \% \mathrm{HCl}$, the solution was extracted with four $100 \mathrm{ml}$ portions of ether, the ether washed once with saturated sodium chloride solution dried over magnesium sulfate and concentrated in vacuum. The remaining pale yellow oil was distilled at 96$98^{\circ} \mathrm{C}$ to give 3-aminocyclohexa-1,4-diene-1carboxylic acid.

\section{Reduction of $m$-nitrobenzoic acid by photochemical electron transfer method [4] (Method II)}

The photoreduction of (I) was carried out in Pyrex vessels (>300 nm) with a $500 \mathrm{~W}$ high-pressure mercury lamp under an argon atmosphere at room temperature. The excitation of a 2-propanol solution of m-nitrobenzoic acid 1 (5 mM) and $\mathrm{NaOH}(200 \mathrm{mM})$ for $6 \mathrm{~h}$ exclusively afforded 5aminocyclohex-2-ene-carboxylic acid in 72\% isolated yield. The efficiency of this photoreduction was highly dependent on both the nature of the substrate and the concentration of $\mathrm{NaOH}$; further, the use of $\mathrm{KOH}$ or tetrabutylammonium hydroxide instead of $\mathrm{NaOH}$ resulted in a low yield of the reduction product fig. 1 [4].

\section{Reduction of $\boldsymbol{m}$-nitrobenzoic acid by THF and naphthalene method (Method III) [5]}

We also, discovered that the same reduction of $\mathrm{m}$-nitrobenzoic acid could be performed in THF (no ammonia) with lithium metal and catalytic amounts of naphthalene used as an electron shuttle. We feel that removing the need for ammonia solvent will make the partial reduction reaction more practicable, especially on a large scale, and may also allow us to quench reduction reactions with sensitive electrophiles that would otherwise react with ammonia itself. Above three different reduction procedures has been carried out to check the practical yield of different modifications in Birch reduction. The compound selected for the birch reduction is m-nitrobenzoic acid as its was hypothise that the reduce product to $\mathrm{m}$-nitrobenzoic acid i.e the 3-aminocyclohexa- 
1,5-diene-1-carboxylic acid have structural similarity with GABA. The percentage yield of 3aminocyclohexa-1,4-diene-1-carboxylic acid with three modifications is $84,72,69 \%$ respectively.

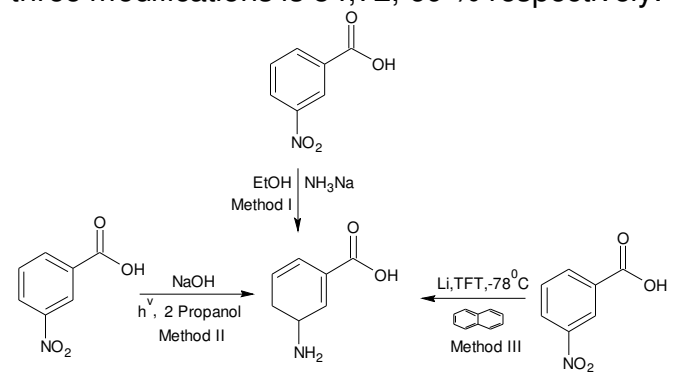

Fig. 1- Birch type reduction of Mm-nitro benzoic acid with three different method

The synthesis of $3-[1,3,4-t h i a d i a z o l e-2-y l]-2-$ styryl 5,8-dihydroquinazoline-4(3H)-ones :

The synthesis of 3-[1,3,4-thiadiazole-2-yl]-2-styryl 5,8-dihydroquinazoline-4 (3H)-ones was accomplished as shown in Figs. 2 and 3. 2methyl-3-(1,3,4-thiadiazol-2-yl)-5,8-

dihydroquinazolin- $4(3 H)$-one were obtained by refluxing 2-methyl-5,8-dihydro-4H-3,1benzoxazin-4-one III [15] with the amine derivatives 4 according to Fig. 2. The amino derivative $4[16,17]$ was obtained by oxidative cyclization of thiosemicarbazone III (obtained by condensation of aromatic aldehyde I and thiosemicarbazide II) in the presence of ferric chloride according to figure 3. 3-[1,3,4thiadiazole-2-yl]-2-styryl 5,8-dihydroquinazoline-4 $(3 \mathrm{H})$-ones was synthesized by the steps mention in fig 2 . In this method 3-[ 1,3,4-thiadiazole-2-yl]2-styryl 5,8-dihydroquinazoline-4 (3H)-ones V was obtained by refluxing equimolar amount of 2methyl-3-(1,3,4-thiadiazol-2-yl)-5,8-

dihydroquinazolin- $4(3 H)$-one and aromatic aldehyde in glacial acetic acid. The structures of the new compounds were elucidated by analytical and spectroscopic measurements. Thin layer chromatography (TLC) was run throughout the reaction to optimize the reaction for purity and completion. The physical and chemical data for the newly synthesized compounds are presented in Table 4.

\section{Pharmacology}

The new derivatives obtained from the reaction sequence were injected intraperitoneally into mice and evaluated in the maximal electroshock (MES), subcutaneous pentylenetetrazole (scPTZ) and neurotoxicity screens, using doses of 30, 100 and $300 \mathrm{mg} / \mathrm{kg}$ at two different time intervals. This Anticonvulsant evaluation of the synthesized compounds was done by the anticonvulsant drug development (ADD) program protocol .These data are presented in Table 1. These compounds were also screened for their CNS behavioral activity in mice using actophotometer and Porsolt's swim pool test in rats and results are presented in Tables 2 and 3.

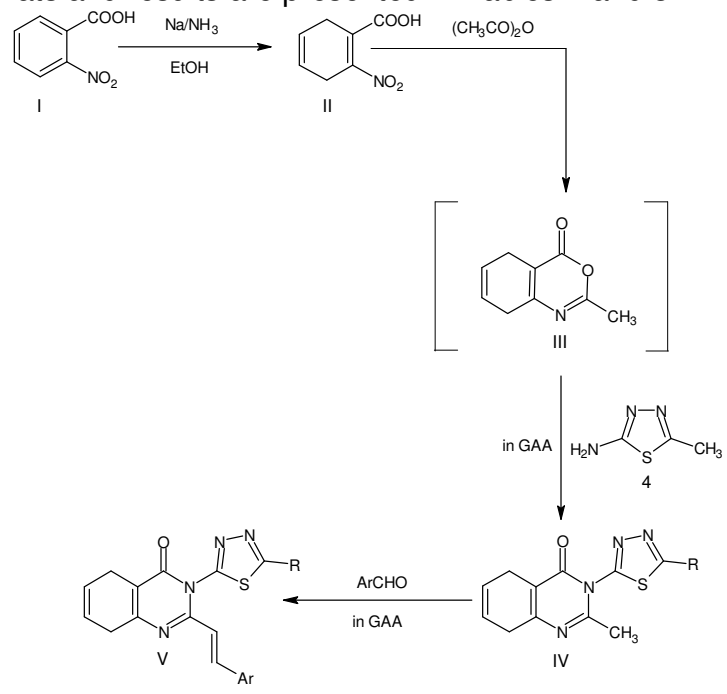

Fig. 2- Scheme for the synthesis of title compounds

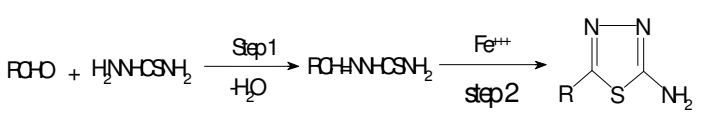
1

2

3

Fig. 3- Scheme for the synthesis of 2-amino-5aryl-1,3,4-thiadiazoles

\section{Results and discussions}

Initial anticonvulsant activity and neurotoxicity data for the quinazolinone analogs are reported in Table 2, along with the literature data on phenytoin, carbamazepine, sodium valproate and phenobarbital [18, 19]. In this series all the quinazolinone analogs showed more potent sedative hypnotic and CNS depressant activities than anticonvulsant activity. In the earlier reports it was highlighted that the presence of electron rich atom/group attached at the para position of the aryl ring showed increased potency in the MES screen. Compounds a,1, 4,5,9 were found to exhibit anticonvulsant activity in MES screen, however, compound 4 showed potency similar to standard drug (phenytoin, carbamazepine) without any neurotoxicity. Compound 4 displayed activity in the MES screen after $0.5 \mathrm{~h}(100 \mathrm{mg} / \mathrm{kg})$ and $4 \mathrm{~h}(100 \mathrm{mg} / \mathrm{kg})$ while it was active at both $0.5 \mathrm{~h}(300 \mathrm{mg} / \mathrm{kg})$ and $4 \mathrm{~h}(300 \mathrm{mg} / \mathrm{kg})$ in the scPTZ test. This compound exhibited rapid onset of action and long duration of activity. Compounds 2, 3, 4,5, 6, 7, 8, and compound a did not show any activity in MES as well as in scPTZ after 0.5 and $4 \mathrm{~h}$. compound 1 showed anticonvulsant activity st 0.5 and $4 \mathrm{~h}$ in both test model where as compound 9 showed anticonvulsant activity in SCPTZ screen. Compounds 1 and 9 showed neurotoxicity after $0.5 \mathrm{~h}$ at $300 \mathrm{mg} / \mathrm{kg}$ body weight. Experimental 
results indicated that our compound exhibited better sedative-hypnotic and CNS depressant activities as compared to anticonvulsant activity. All the compounds were screened for behavior study and CNS depressant activity. In the behavioral study using actophotometer scoring technique, compounds showed decrease in locomotor activity between $7 \%$ and $70 \%$ where $7 \%$ was the lowest and $70 \%$ was the maximal decrease in locomotor activity when compared to phenytoin as reported in Table 3 . Compound 4 and 'a' was equipotent to phenytoin in decreasing $\%$ locomotor activity. All the compounds except 2,3,6 exhibited more than $50 \%$ decrease in locomotor activity $(\mathrm{p}<0.02)$ after $1 \mathrm{~h}$. Generally compounds possessing higher log $p$ value showed higher decrease in locomotor activity. Bulkier compounds are more lipophilic and can cross blood brain barrier to exert their effect at CNS. In a similar study using swim pool test, the immobility time after administration of the test compounds were compared with carbamazepine (Table 4). Except for 3, 7 other tested compounds were found to exhibit potent CNS depressant activity $(p<0.05)$ as indicated by increased immobility time. Present study explored that substitution of 1,3,4-thiadiazoles at third position and styryl moiety at second position of 5,8-dihydroquinazoline-4 $(3 \mathrm{H})$-ones.

\section{Chemistry \\ Synthesis of 2-amino 5-aryl 1'3'4'-thiadiazole \\ Synthesis of 2-amino 5-aryl 1'3'4'-thiadiazole was synthesized following two steps.}

Step 1: Synthesis of thiosemicarbazones

Aromatic aldehyde I $(0.2 \mathrm{M})$ in warm alcohol (300 $\mathrm{mL})$ and thiosemicarbazide II $(0.2 \mathrm{M})$ in warm water $(300 \mathrm{~mL})$ were mixed slowly with continuous stirring. The product separated immediately on cooling which was filtered with suction, dried and recrystallised in $75 \%$ ethanol to yield III. Physicochemical properties are presented in Table 4.

Step-2: Synthesis of 2-amino-5-aryl 1'3'4'thiadiazoles

Thiosemicarbazone III (0.05 M) was suspended in $300 \mathrm{ml}$ warm water; $\mathrm{FeCl} 3(0.15 \mathrm{M})$ in $300 \mathrm{ml}$ water was added quantitatively, slowly with constant stirring. The contents were heated at $80-90{ }^{\circ} \mathrm{C}$ for $45 \mathrm{~min}$. Solution was filtered hot and then citric acid $(0.11 \mathrm{M})$ and sodium citrate $(0.05$ M) were added. The resulting mixture was divided into 4 parts and each part was neutralized separately with ammonia $(10 \%)$. The required amine separated out, filtered with suction, dried and recrystallised with appropriate solvent.

Synthesis of 2-methyl-3-(5-substituted-1,3,4thiadiazol-2-yl)-5,8-dihydroquinazolin-4(3H)one
Anthranilic acid $1(0.01 \mathrm{M})$ was reduced using Birch reduction condition to 2-aminocyclohexa1,4-diene-1-carboxylic acid. 2-aminocyclohexa1,4-diene-1-carboxylic acid and acetic anhydride were re-fluxed under anhydrous condition for $4 \mathrm{~h}$. Excess of acetic anhydride was distilled off under reduced pressure. To the mixture obtained, amines $4(0.01 \mathrm{M})$ in glacial acetic acid was added and refluxed for $4 \mathrm{~h}$. Obtained reaction mixture was poured into crushed ice and left overnight. The solid, which separated out, was filtered, washed thoroughly with cold distilled water, dried and recrystallised from hot ethanol.

\section{Synthesis of title compound}

The title compounds were synthesized by following the procedure reported earlier by [4044]. A solution of $4(0.01 \mathrm{M})$ and benzaldehyde $(0.01 \mathrm{M})$ were reacted with glacial acetic acid (10 $\mathrm{ml}$ ) and refluxed for $12 \mathrm{~h}$. The solid 4 which separated out was filtered with suction and recrystallised from dimethylformamide to give pure compound. The physical data of the styryl 5,8-diquinazolinone are given in Table 4.

The IR spectra, ${ }^{13} \mathrm{C}$ NMR spectra and ${ }^{1} \mathrm{H}$ NMR spectra of the title compounds are as follows:

1. IR $\left(\mathrm{cm}^{-1}\right) 1693(\mathrm{C}=\mathrm{O}), 1650(\mathrm{C}=\mathrm{C})$ Alkene, $1530(\mathrm{C}=\mathrm{N}), 1317$ (CN), $688(\mathrm{CS}) ;{ }^{13} \mathrm{C}$ NMR $(300$ $\mathrm{MHz}$, ठ) 168 (C-4), 162.4 (C-2), 112 (C-11), 136 (C-12), 136.5 (C-1), 135 (C-18); ${ }^{1} \mathrm{H}$ NMR (300 $\mathrm{MHz}, \delta) 5.16(\mathrm{~d}, 1 \mathrm{H}$, olefinic $\mathrm{CH}, \mathrm{J}=15.2 \mathrm{~Hz})$, 6.6-7.92 (a set of signals, $12 \mathrm{H}$, aromatic protons and olefinic $\mathrm{CH}$ ). 13C NMR (300 MHz, d) 168 (C4), 162.4 (C-2), 112 (C-11), 136 (C-12), 136.5 (C100), 135 (C-13), 112 (Cx of styryl group), 122.1 (C8 of $4(3 \mathrm{H})$ quinazolinone ring), 126.9 (C10 of dihydroquinazoline-4(3H)-ones ), 127.0 (C2" and $\mathrm{C}_{6}$ " of phenyl ring of 1,3,4-thiadiazole ring), 127.1 (C6 of dihydroquinazoline-4(3H)-ones ring), 127.6 ( $\mathrm{Cb}$ of phenyl at $\mathrm{C}-2$ of dihydroquinazoline$4(3 \mathrm{H}$ )-ones ring), 128.5 ( $\mathrm{C} 4$ of phenyl ring of 1,3,4-thiadiazole ring), 129.4 (C3" and $\mathrm{C}_{5}$ "of phenyl ring of 1,3,4-thiadiazole ring), 130.2 (Ca of phenyl ring at $\mathrm{C}-2$ of dihydroquinazoline- $4(3 \mathrm{H})$ ones ring), 136 (Cy of styryl group), 147.8 (C9 of dihydroquinazoline-4(3H)-ones ring).

2. IR $\left(\mathrm{cm}^{-1}\right) 1700(\mathrm{C}=\mathrm{O}), 1611(\mathrm{C}=\mathrm{C})$ Alkene, $1520(\mathrm{C}=\mathrm{N}), 1313(\mathrm{CN}), 675(\mathrm{CS}) ;{ }^{13} \mathrm{C}$ NMR (300 $\mathrm{MHz}, \delta) 161$ (C-2), 161.5 (C-4), 114.7 (C-11), 136 (C-12), $136.5\left(\mathrm{C}^{N}{ }^{N}\right), 134(\mathrm{C}-13), 55.4\left(\mathrm{C}_{\mathrm{A}}\right) ;{ }^{1} \mathrm{H}$ $\operatorname{NMR}(300 \mathrm{MHz}, \delta) 3.73\left(\mathrm{~s}, 3 \mathrm{H}, \mathrm{CH}_{3}\right), 5.74(\mathrm{~d}, 1 \mathrm{H}$, olefinic $\mathrm{CH}$

$\mathrm{J}=15.5 \mathrm{~Hz}$ ), $6.83-8.00$ (a set of signals, $13 \mathrm{H}$, aromatic protons and olefinic $\mathrm{CH} 13 \mathrm{C}$ NMR (300 $\mathrm{MHz}$, d) 168 (C-4), 162.4 (C-2), 114 (C-11), 138 (C-12), 136 (C-100), 135 (C-13), 112 (Cx of styryl group), 121.1 (C8 of $4(3 \mathrm{H})$ quinazolinone ring), 126.9 (C10 of dihydroquinazoline-4(3H)-ones ), 126.0 (C2" and $\mathrm{C}_{6}$ " of phenyl ring of 1,3,4thiadiazole ring), $126.1 \quad(\mathrm{C} 6$ of dihydroquinazoline-4(3H)-ones ring), 127.6 ( $\mathrm{Cb}$ 
of phenyl at C-2 of dihydroquinazoline- $4(3 \mathrm{H})$ ones ring), 128.5 (C4 of phenyl ring of 1,3,4thiadiazole ring), 128.4 (C3" and $\mathrm{C}_{5}$ "of phenyl ring of 1,3,4-thiadiazole ring), 130.2 (Ca of phenyl ring at $\mathrm{C}-2$ of dihydroquinazoline-4(3H)-ones ring), 136 (Cy of styryl group), 146.8 (C9 of dihydroquinazoline-4(3H)-ones ring).

3. IR ( $\left.\mathrm{cm}^{-1} 1\right) 1691(\mathrm{C}=\mathrm{O}), 1640(\mathrm{C}=\mathrm{C})$ Alkene, $1530(\mathrm{C}=\mathrm{N}), 1275(\mathrm{CN}), 773(\mathrm{CS}) ;{ }^{13} \mathrm{C}$ NMR $(\delta)$ 165 (C-2), 168 (C-4), 112 (C-11), 136 (C-12), 133.5 (C-100), 134.9 (C-13), 21.4 (CA); 1H NMR (300 MHz, d) $2.35\left(\mathrm{~s}, 3 \mathrm{H}, \mathrm{CH}_{3}\right), 5.84(\mathrm{~d}, 1 \mathrm{H}$, olefinic $\mathrm{CH}, \mathrm{J}=15.2 \mathrm{~Hz}$ ), 6.12-7.85 (a set of signals, $13 \mathrm{H}$, aromatic protons and olefinic $\mathrm{CH}$ ). 13C NMR (300 MHz, d) 168 (C-4), 162.4 (C-2), 112 (C-11), 136 (C-12), 136.5 (C-100), 135 (C13), 112 (Cx of styryl group), 122.1 (C8 of $4(3 \mathrm{H})$ quinazolinone ring), $126.9 \quad$ (C10 of dihydroquinazoline-4(3H)-ones ), 127.0 (C2" and $\mathrm{C}_{6}$ " of phenyl ring of 1,3,4-thiadiazole ring), 127.1 (C6 of dihydroquinazoline-4(3H)-ones ring), $127.6(\mathrm{Cb}$ of phenyl at $\mathrm{C}-2$ of dihydroquinazoline$4(3 \mathrm{H})$-ones ring), 128.5 (C4 of phenyl ring of 1,3,4-thiadiazole ring), 129.4 (C3" and $\mathrm{C}_{5}$ "of phenyl ring of 1,3,4-thiadiazole ring), 130.2 (Ca of phenyl ring at $\mathrm{C}-2$ of dihydroquinazoline- $4(3 \mathrm{H})$ ones ring), 136 (Cy of styryl group), 147.8 (C9 of dihydroquinazoline-4(3H)-ones ring).

4. IR $\left(\mathrm{cm}^{-1}\right) 1700(\mathrm{C}=\mathrm{O}), 1668(\mathrm{C}=\mathrm{C})$ Alkene, $1591(\mathrm{C}=\mathrm{N}), 1326(\mathrm{CN}), 752(\mathrm{CS}) ;{ }^{13} \mathrm{C}$ NMR $(\delta)$ 165 (C-2), 168 (C-4), 112 (C-11), 136.4 (C-12), 134.6 (C-100), 135 (C-13); $1 \mathrm{H}$ NMR (300 MHz, d) $5.52(\mathrm{~d}, 1 \mathrm{H}$, olefinic $\mathrm{CH}, \mathrm{J}=15.2 \mathrm{~Hz}), 6.80-7.48$ (a set of signals, $13 \mathrm{H}$, aromatic protons and olefinic $\mathrm{CH}) .13 \mathrm{C}$ NMR (300 MHz, d) 168 (C-4), 162.4 (C-2), 112 (C-11), 136 (C-12), 136.5 (C-100), 135 (C-13), 112 (Cx of styryl group), 122.1 (C8 of $4(3 \mathrm{H})$ quinazolinone ring), $126.9 \quad(\mathrm{C} 10$ of dihydroquinazoline-4(3H)-ones ), 127.0 (C2" and $\mathrm{C}_{6}$ " of phenyl ring of 1,3,4-thiadiazole ring), 127.1 (C6 of dihydroquinazoline-4(3H)-ones ring), 127.6 ( $\mathrm{Cb}$ of phenyl at $\mathrm{C}-2$ of dihydroquinazoline$4(3 \mathrm{H})$-ones ring), 128.5 (C4 of phenyl ring of 1,3,4-thiadiazole ring), 129.4 (C3" and C F" $_{5}$ "of phenyl ring of 1,3,4-thiadiazole ring), 130.2 (Ca of phenyl ring at $\mathrm{C}-2$ of dihydroquinazoline- $4(3 \mathrm{H})$ ones ring), 136 (Cy of styryl group), 147.8 (C9 of dihydroquinazoline-4(3H)-ones ring).

5. IR $\left(\mathrm{cm}^{-1}\right) 1700(\mathrm{C}=\mathrm{O}), 1614(\mathrm{C}=\mathrm{C})$ Alkene, $1555(\mathrm{C}=\mathrm{N}), 1326(\mathrm{CN}), 760(\mathrm{CS}) ;{ }^{13} \mathrm{C}$ NMR $(\delta)$ 160.2 (C-2), 168.8 (C-4), 112 (C-11), 136 (C-12), 137.9 (C-100), 134 (C-13); 1H NMR (300 MHz, d) $5.12(\mathrm{~d}, 1 \mathrm{H}$, olefinic $\mathrm{CH}, \mathrm{J}=15.4 \mathrm{~Hz}), 6.41-7.49$ (a set of signals, $13 \mathrm{H}$, aromatic protons and olefinic $\mathrm{CH})$. 13C NMR (300 MHz, d) 168 (C-4), 162.4 (C-2), 112 (C-11), 136 (C-12), 136.5 (C-100), 135 (C-13), 112 (Cx of styryl group), 122.1 (C8 of $4(3 \mathrm{H})$ quinazolinone ring), 126.9 (C10 of dihydroquinazoline-4(3H)-ones ), 127.0 (C2" and
$\mathrm{C}_{6}$ " of phenyl ring of 1,3,4-thiadiazole ring), 127.1 (C6 of dihydroquinazoline-4(3H)-ones ring), 127.6 ( $\mathrm{Cb}$ of phenyl at $\mathrm{C}-2$ of dihydroquinazoline$4(3 \mathrm{H})$-ones ring), 128.5 (C4 of phenyl ring of 1,3,4-thiadiazole ring), 129.4 (C3" and $\mathrm{C}_{5}$ "of phenyl ring of 1,3,4-thiadiazole ring), 130.2 (Ca of phenyl ring at $\mathrm{C}-2$ of dihydroquinazoline- $4(3 \mathrm{H})$ ones ring), 136 (Cy of styryl group), 147.8 (C9 of dihydroquinazoline-4(3H)-ones ring).

6.IR (cm $\left.{ }^{-1}\right) 1737(\mathrm{C}=\mathrm{O}), 1610(\mathrm{C}=\mathrm{C})$ Alkene, $1532(\mathrm{C}=\mathrm{N}), 1269(\mathrm{CN}), 733(\mathrm{CS}) ;{ }^{13} \mathrm{C}$ NMR $(\delta)$ 167 (C-2), 168.9 (C-4), 112 (C-4), 136 (C-12), 134 (C-100), 134 (C-13), 125 (CA), 130 (CB); $1 \mathrm{H}$ NMR (300 MHz, d) $5.60(\mathrm{~d}, 1 \mathrm{H}$, olefinic $\mathrm{CH}, \mathrm{J} 1 / 4$ 15.6 Hz), $6.99(\mathrm{~d}, 2 \mathrm{H}$, olefinic $\mathrm{CH}), 6.78-8.01$ (a set of signals, $14 \mathrm{H}$, aromatic protons and olefinic CH). 13C NMR (300 MHz, d) 169 (C-4), 164.4 (C-2), 115 (C-11), 137 (C-12), 137.5 (C-100), 136 (C-13), 113 (Cx of styryl group), 122.1 (C8 of $4(3 \mathrm{H})$ quinazolinone ring), 126.9 (C10 of dihydroquinazoline-4(3H)-ones ), 127.0 (C2" and $\mathrm{C}_{6}$ " of phenyl ring of 1,3,4-thiadiazole ring), 127.1 (C6 of dihydroquinazoline-4(3H)-ones ring), 128.6 (Cb of phenyl at $\mathrm{C}-2$ of dihydroquinazoline$4(3 \mathrm{H})$-ones ring), 128.5 ( $\mathrm{C} 4$ of phenyl ring of 1,3,4-thiadiazole ring), 128.4 (C3" and $\mathrm{C}_{5}$ "of phenyl ring of 1,3,4-thiadiazole ring), 130.2 (Ca of phenyl ring at $\mathrm{C}-2$ of dihydroquinazoline- $4(3 \mathrm{H})$ ones ring), 140 (Cy of styryl group), 147.8 (C9 of dihydroquinazoline-4(3H)-ones ring).

7.IR (cm¹) $1700(\mathrm{C}=0), 1620(\mathrm{C}=\mathrm{C})$ Alkene, $1542(\mathrm{C}=\mathrm{N}), 1274(\mathrm{CN}), 136.5(\mathrm{C}-100), 134.5(\mathrm{C}-$ 13), 56 (CA); $1 \mathrm{H} \mathrm{NMR} \mathrm{(300} \mathrm{MHz,} \mathrm{d)} 3.84$ (s, 3H, $\mathrm{CH} 3), 5.82(\mathrm{~d}, 1 \mathrm{H}$, olefinic $\mathrm{CH}, \mathrm{J}=14.4 \mathrm{~Hz}), 6.72-$ 7.94 (a set of signals, $13 \mathrm{H}$, aromatic protons and olefinic $\mathrm{CH}$ ). 13C NMR (300 MHz, d) 169 (C-4), 163.4 (C-2), 114 (C-11), 138 (C-12), 138.5 (C100), 136 (C-13), 114 (Cx of styryl group), 123.1 (C8 of $4(3 \mathrm{H})$ quinazolinone ring), 126.9 (C10 of dihydroquinazoline-4(3H)-ones ), 130.0 (C2" and $\mathrm{C}_{6}$ " of phenyl ring of 1,3,4-thiadiazole ring), 127.1 (C6 of dihydroquinazoline-4(3H)-ones ring), 127.6 ( $\mathrm{Cb}$ of phenyl at $\mathrm{C}-2$ of dihydroquinazoline$4(3 \mathrm{H})$-ones ring), 128.5 ( $\mathrm{C} 4$ of phenyl ring of 1,3,4-thiadiazole ring), 130.4 (C3" and $\mathrm{C}_{5}$ "of phenyl ring of 1,3,4-thiadiazole ring), 130.2 (Ca of phenyl ring at $\mathrm{C}-2$ of dihydroquinazoline- $4(3 \mathrm{H})$ ones ring), 139 (Cy of styryl group), 147.8 (C9 of dihydroquinazoline-4(3H)-ones ring).

8. IR ( $\left.\mathrm{cm}^{-1} 1\right) 1739(\mathrm{C}=\mathrm{O}), 1642(\mathrm{C}=\mathrm{C})$ Alkene, $1542(\mathrm{C}=\mathrm{N}), 1334(\mathrm{CN}), 759$ (CS); ${ }^{13} \mathrm{C}$ NMR $(\delta)$ 167 (C-2), 168.6 (C-4), 112 (C-11), 136 (C-12), 128.8 (C-100), 131.4 (C-13), 55.5 (CA), 56 (CB); $1 \mathrm{H}$ NMR (300 MHz, d) 3.63 (s, 3H, CH3), 3.72 (s, $3 \mathrm{H}, \mathrm{CH} 3), 5.76(\mathrm{~d}, 1 \mathrm{H}$, olefinic $\mathrm{CH}, \mathrm{J}=15.0 \mathrm{~Hz})$, 6.60-7.86 (a set of signals, $12 \mathrm{H}$, aromatic protons and olefinic $\mathrm{CH})$. 13C NMR (300 MHz, d) $169(\mathrm{C}-$ 4), 162.4 (C-2), 117 (C-11), 139 (C-12), 140.5 (C100), 136 (C-13), 113 (Cx of styryl group), 122.1 
(C8 of $4(3 \mathrm{H})$ quinazolinone ring), 126.9 (C10 of dihydroquinazoline-4(3H)-ones ), 129.0 (C2" and $\mathrm{C}_{6}$ " of phenyl

ring of 1,3,4-thiadiazole ring), 127.1 (C6 of dihydroquinazoline-4(3H)-ones ring), $127.6(\mathrm{Cb}$ of phenyl at $\mathrm{C}-2$ of dihydroquinazoline- $4(3 \mathrm{H})$ ones ring), 128.5 (C4 of phenyl ring of 1,3,4thiadiazole ring), 130.4 (C3" and $\mathrm{C}_{5}$ "of phenyl ring of 1,3,4-thiadiazole ring), 132.2 (Ca of phenyl ring at $\mathrm{C}-2$ of dihydroquinazoline-4(3H)-ones ring), 136 (Cy of styryl group), 149.8 (C9 of dihydroquinazoline-4(3H)-ones ring).

9.IR ( $\mathrm{cm}^{-1}$ ) $1701(\mathrm{C}=\mathrm{O}), 1637(\mathrm{C}=\mathrm{C})$ Alkene, $1530(\mathrm{C}=\mathrm{N}), 1267$ (CN), $774(\mathrm{CS}) ;{ }^{13} \mathrm{C}$ NMR (ס) 165 (C-2), 168 (C-4), 112 (C-11), 136 (C-12), 133.5 (C-100), 131.4 (C-13), 21.4 (CA), 56 (CB); 1H NMR (300 MHz, d) 2.32 (s, 3H, CH3), 3.74 (s, $3 \mathrm{H}, \mathrm{CH} 3), 5.85(\mathrm{~d}, 1 \mathrm{H}$, olefinic $\mathrm{CH}, \mathrm{J}=15.2 \mathrm{~Hz})$, 6.74-7.10 (a set of signals, $12 \mathrm{H}$, aromatic protons and olefinic $\mathrm{CH}$ ). 13C NMR (300 MHz, d) 168 (C4), 169.4 (C-2), 117 (C-11), 141 (C-12), 139.5 (C100), 138 (C-13), 112 (Cx of styryl group), 122.1 (C8 of $4(3 \mathrm{H})$ quinazolinone ring), 126.9 (C10 of dihydroquinazoline-4(3H)-ones ), 129.0 (C2" and $\mathrm{C}_{6}$ " of phenyl

ring of 1,3,4-thiadiazole ring), 129.1 (C6 of dihydroquinazoline-4(3H)-ones ring), 127.6 ( $\mathrm{Cb}$ of phenyl at $\mathrm{C}-2$ of dihydroquinazoline- $4(3 \mathrm{H})$ ones ring), 128.5 (C4 of phenyl ring of 1,3,4thiadiazole ring), 129.4 (C3" and $\mathrm{C}_{5}$ "of phenyl ring of 1,3,4-thiadiazole ring), 130.2 (Ca of phenyl ring at $\mathrm{C}-2$ of dihydroquinazoline-4(3H)-ones ring), 139 (Cy of styryl group), 150.8 (C9 of dihydroquinazoline-4(3H)-ones ring).

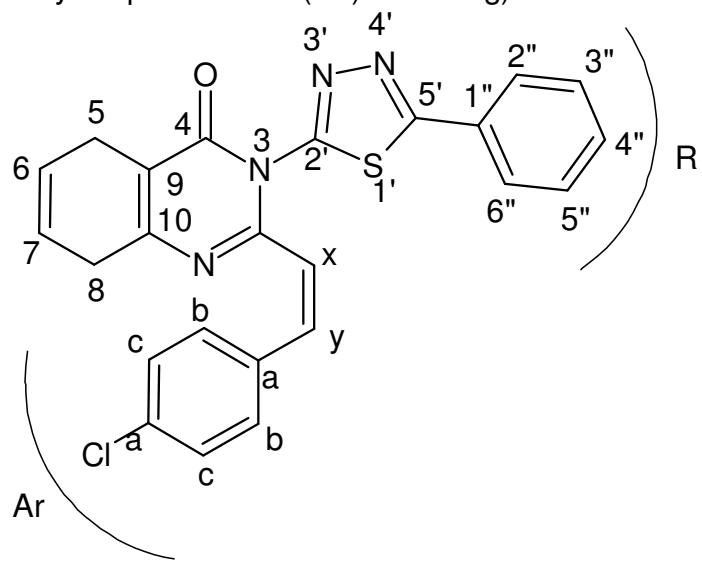

\section{Pharmacology}

The anticonvulsant evaluation was undertaken using reported procedure [45-49]. Male albino mice (CF-1 strain or swiss, $18 \mathrm{e} 25 \mathrm{~g}$ ) and rats (SpragueeDawley or Wistar, 100e150 g) were used as experimental animals. The tested compounds were suspended in polyethylene glycol 400.

\section{Anticonvulsant screening}

Initially all the compounds were administered i.p. in a volume of $0.01 \mathrm{ml} / \mathrm{g}$ body weight for mice and $0.004 \mathrm{ml} / \mathrm{g}$ body weight for rats at doses of $30,100,300 \mathrm{mg} / \mathrm{kg}$ to one to four animals. Activity was established using the MES and scPTZ test and these data are presented in Table 1.

\section{Neurotoxicity screening}

Minimal motor impairment was measured in mice by the rotorod test. The mice were trained to stay on an accelerating rotorod that rotated at six revolutions per minute. The rod diameter was 3.2 $\mathrm{cm}$. Neurotoxicity was indicated by the inability of the animal to maintain equilibrium on the rod for at least $1 \mathrm{~min}$ in each of the three trials.

\section{Behavioral testing}

The titled compounds $(100 \mathrm{mg} / \mathrm{kg})$ were screened for their behavioral effect using actophotometer [20]at $30 \mathrm{~min}$ and $1 \mathrm{~h}$ after drug administration. The behavior of animals inside the photocell was recorded as a digital score. Increased scores suggest good behavioral activity. The activity of the compounds were at maximum at $1 \mathrm{~h}$, therefore, the activity values at $1 \mathrm{~h}$ were used to calculate \% decrease in locomotor activity. The control group animals were administered PEG 400. The observations are tabulated as Table 2.

\section{CNS depressant activity}

The forced swim pool method described earlier [21] was followed. Wistar rats were placed in chamber (diameter $45 \mathrm{~cm}$, height $20 \mathrm{~cm}$ ) containing water up to a height of $15 \mathrm{~cm}$ at $25_{-} 2$ C. Two swim sessions were conducted an initial 15 min pretest, followed by a 5 min test session $24 \mathrm{~h}$ later. The animals were drug administrated $(100 \mathrm{mg} / \mathrm{kg}$ ) the test compound i.p. $30 \mathrm{~min}$ before the test session. The period of immobility (passive floating without struggling, making only those movements which are necessary to keep its head above the surface of water) during the 5 min test period was measured. The results are presented in Table 3.

\section{References}

[1] Birch A.J. and Smith H. (1950) Rev. Chem. Soc. (69)4, 553.

[2] Donohoe T.J. Garg R. and Stevenson C.A (1996) Tetrahedron Asymmetry, (7) 2, 317-344.

[3] Birch A.J and. Slobbe J (1976) Heterocycles 5(2), 905.

[4] Yoshimi Y., Ishise A., Oda H. and Moriguchi Y. (2000) Tetrahedron Letters 49, 1331-1334.

[5] Donohoe T.J., Harji R.R. and Cousins R.C. (2000) Tetrahedron Letters 41, 13311334. 
[6] Costanzo M.J.,Patel M.N., Petersen K.A and Vogt P.F. (2009) $13^{\text {th }}$ Annual Green Chemistry and Engineering Conference. 36, 1105.

[7] Armarego W.L.F. (1979) Adv. Heterocycl. Chem. 24, 1-62.

[8] Fisnerova L., Brunova B., Kocfeldova Z ., Tikalova J. and Maturova E. (1991) Collect. Czech. Chem. Commun. 56, 2373-2381.

[9] Saxena S., Verma M., Saxena A.K. and Shanker K. (1991) Indian J. Pharm. Sci. $53,48-52$.

[10] GravierD., Dupin J.P., Casadebaig F., Hou G., Boisseau M. and Bernard H. (1992) Pharmazie. 47, 91-94.

[11] Boltze K.H., Dell H.D., Lehwald H., Loranz D. and Ruberg-schweer M. (1963) Arzneim.-Forsch./Drug Res. 13, 688692.

[12] Wolfe J.F., Rathman T.L., Sleevi M.C., Campbell J.A. and Greenwood T.D. (1990) J. Med. Chem. 33, 161-166.

[13] Jain S.K. and Mishra P. (2000) Asian J. Chem. 12, 1341-1343.
[14] Furniss B.S., Hannaford A.J., Smith P.W.G. and Tatchell A.R. (2008) Vogal's textbook of Practical Chemistry. $5^{\text {th }}$ edn, 78-79.

[15] Yoshimi Y., Higuchi M., Itou T. and Hatanaka M. (2004) Chem. Lett. 1196.

[16] Yoshimi Y., Itou T. and Hatanaka M. (2006) Tetrahedron Lett. 47, 3257.

[17] Jatav V., Jain S.K., Kashaw S.K. and Mishra P. (2006) Indian J. Pharm. Sci. 7360-362.

[18] Dimmock J.R., Puthucode R.N., Smith J.M., Hetherington M., Quail J.W., Pugazhenthi U., Lechler T. and Stables J.P. (1996) J. Med. Chem. 39,39843997.

[19] Flaherty P.T., Greenwood T.D., Manhein A.L. and Wolfe J.F. (1996) J. Med. Chem.39,1509-1513.

[20] Boissoer J.R. and Simon P. (1965) Arch. Int. Pharmacodyn. Ther. 158, 212-214.

[21] Porsolt R.D., Anton G., Blanet N. and Jalbre M. (1978) Eur. J. Pharm. 47, 379-386. 
Table 1- Anticonvulsant activity and minimal motor impairment of 3-[5-substituted 1,3,4-thiadiazole-2-yl]-2-styryl dihydroquinazoline-4(3H)-ones and compound

\begin{tabular}{|c|c|c|c|c|c|c|}
\hline \multirow{3}{*}{ Derivative no } & \multicolumn{6}{|c|}{ Intraperitoneal injection in mice ${ }^{a}$} \\
\hline & \multicolumn{2}{|c|}{ MES screen } & \multicolumn{2}{|c|}{ scPTZ screen } & \multicolumn{2}{|c|}{ Neurotoxicity screen } \\
\hline & $0.5 \mathrm{~h}$ & $4 \mathrm{~h}$ & $0.5 \mathrm{~h}$ & $4 \mathrm{~h}$ & $0.5 \mathrm{~h}$ & $4 \mathrm{~h}$ \\
\hline 1 & 100 & 300 & 300 & $300^{b}$ & - & - \\
\hline 2 & - & - & - & - & 300 & - \\
\hline 3 & - & - & - & - & 300 & - \\
\hline 4 & - & - & - & - & - & - \\
\hline 5 & - & - & - & - & 300 & - \\
\hline 6 & - & - & - & - & $300^{C}$ & - \\
\hline 7 & - & - & - & - & 100 & - \\
\hline 8 & - & - & - & - & 300 & - \\
\hline 9 & - & - & - & 300 & - & - \\
\hline$a$ & 100 & 100 & 300 & 300 & - & - \\
\hline Phenytoin $^{d}$ & 30 & 30 & & & 100 & 100 \\
\hline Carbamazepine $^{\mathrm{d}}$ & 30 & 100 & 100 & 300 & 100 & 300 \\
\hline Sodium vaporate & - & - & 300 & - & - & - \\
\hline Phenobarbitals $^{\mathrm{d}}$ & 100 & 30 & 30 & 300 & 100 & 300 \\
\hline
\end{tabular}

a: Doses of 30,100 and $300 \mathrm{mg} / \mathrm{kg}$ were administered. The values in the table indicate the minimum dose whereby bioactivity was demonstrated in half or more of the mice. The animals were examined 0.5 and $4 \mathrm{~h}$ after the injections were made; the symbol (e) indicates the absence of activity at maximum dose administered (300 mg/kg).

b: Died during test at $300 \mathrm{mg} / \mathrm{kg}$ without seizure.

c: Neurotoxicity at $100 \mathrm{mg} / \mathrm{kg}(0.25 \mathrm{~h}, 1 \mathrm{~h})$.

d: Data from Refs. [9-11].

Table 2- Behavioral study of 3-[5-substituted 1,3,4-thiadiazole-2-yl]-2-styryl dihydroquinazoline-4(3H)-ones

\begin{tabular}{|c|c|c|c|c|}
\hline \multirow{4}{*}{ 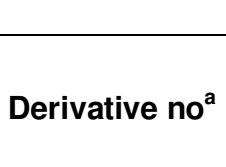 } & \multirow{2}{*}{\multicolumn{3}{|c|}{ activity score ${ }^{\mathrm{b}}$ and compound }} & \multirow{4}{*}{$\%$ Inhibition } \\
\hline & & & & \\
\hline & \multirow{2}{*}{$\begin{array}{l}\text { Control } \\
\text { (24 h prior) }\end{array}$} & \multicolumn{2}{|l|}{ Post treatment } & \\
\hline & & 0.5 h After & 1 h After & \\
\hline 1 & $579.32 \pm 20.78$ & $492.31 \pm 26.78$ & $269.75 \pm 11.69$ & 53 \\
\hline 2 & $406.04 \pm 11.26$ & $381.82 \pm 9.69$ & $246.36 \pm 11.89$ & 39 \\
\hline 3 & $472.24 \pm 10.42$ & $541.70 \pm 19.92$ & $437.50 \pm 21.11$ & 7 \\
\hline 4 & $518.10 \pm 9.97$ & $357.62 \pm 11.30$ & $250.04 \pm 12.49$ & 52 \\
\hline 5 & $554.16 \pm 10.62$ & $374.57 \pm 10.60$ & $265.72 \pm 12.70$ & 52 \\
\hline 6 & $549.87 \pm 17.52$ & $399.87 \pm 2.21$ & $499.92 \pm 09.93$ & 9 \\
\hline 7 & $487.63 \pm 9.21$ & $431.24 \pm 9.12$ & $222.34 \pm 11.92$ & 54 \\
\hline 8 & $482.92 \pm 181.24$ & $333.13 \pm 9.29$ & $195.30 \pm 14.00$ & 60 \\
\hline 9 & $408.96 \pm 21.98$ & $336.46 \pm 4.98$ & $152.10 \pm 16.18$ & 63 \\
\hline$a$ & 536.39_21.12 & $241.01 \_09.32$ & 154.08_28.18 & 69 \\
\hline Phenytoin $^{c}$ & 546.40_31.12 & $251.02-12.32$ & 164.10_30.11 & 70 \\
\hline
\end{tabular}

a: The compounds were tested at a dose of $100 \mathrm{mg} / \mathrm{kg}$ i.p.

$\mathrm{b}$ : Each score represents the means _ SEM of six mice significantly different from the control score at $p<$ 0.05 and NS at $p>0.05$ denotes not significant

(Student's t-test).

c: Tested at $30 \mathrm{mg} / \mathrm{kg}$ p.o. 
Table 3- CNS study on 3-[5-substituted 1,3,4-thiadiazole-2-yl]-2-styryl quinazoline4(3H)-ones by forced swim pool test

\begin{tabular}{|l|l|l|}
\hline \multirow{2}{*}{ Derivative no } & \multicolumn{2}{|c|}{$4(3 H)$-ones by forced swim pool test } \\
\cline { 2 - 3 } & Immobility time $(\mathbf{s})$ \\
\hline Control (24 h prior) & Post treatment (60 min after) \\
\hline 1 & $184.37 \pm 13.15$ & $181.41 \pm 11.54$ \\
\hline 2 & $165.33 \pm 10.83$ & $210.21 \pm 10.71$ \\
\hline 3 & $107.22 \pm 7.14$ & $145.41 \pm 11.49$ \\
\hline 4 & $163.62 \pm 11.19$ & $152.00 \pm 09.76$ \\
\hline 5 & $98.71 \pm 13.92$ & $193.30 \pm 15.33$ \\
\hline 6 & $119.20 \pm 11.31$ & $187.60 \pm 11.84$ \\
\hline 7 & $115.63 \pm 9.73$ & $162.92 \pm 12.72$ \\
\hline 8 & $124.43 \pm 7.39$ & $120.20 \pm 11.91$ \\
\hline 9 & $67.86 \pm 12.44$ & $121.60 \pm 11.73$ \\
\hline a & $197.20 \pm 11.69$ & $218.22 \pm 11.13$ \\
\hline & $102.16 \pm 13.19$ & $198.34 \pm 11.73$ \\
\hline
\end{tabular}

a The compounds were tested at a dose of $100 \mathrm{mg} / \mathrm{kg}$ (oral).

b Each value represents the means _ SEM of six rats significantly different from the control at $p<0.05$ and NS denotes not significant at $p<0.05$ (Student's

t-test).

c Tested at $30 \mathrm{mg} / \mathrm{kg}$ (i.p.).

Table 4- Physical data of 3-[5-substituted 1,3,4-thiadiazole-2-yl]-2-styryl 5,8-dihydroquinazoline-4(3H)-ones

\begin{tabular}{|c|c|c|c|c|c|c|c|c|}
\hline $\begin{array}{l}\text { Code } \\
\text { No. }\end{array}$ & $\mathrm{Ar}$ & $\mathbf{R}$ & $\begin{array}{l}\text { Yield } \\
(\%)\end{array}$ & $\begin{array}{l}\text { M.p. } \\
\left({ }^{\circ} \mathrm{C}\right)\end{array}$ & $\begin{array}{l}\text { Molecular } \\
\text { formula }\end{array}$ & $\begin{array}{l}\text { Molecular } \\
\text { weight }\end{array}$ & $\mathbf{R f}$ & $\begin{array}{l}\text { Log } \\
p^{b}\end{array}$ \\
\hline 1 & $\begin{array}{l}p- \\
\mathrm{ClC}_{6} \mathrm{H}_{4}\end{array}$ & $-\mathrm{C}_{6} \mathrm{H}_{5}$ & 53 & 199 & $\mathrm{C}_{24} \mathrm{H}_{17} \mathrm{ClN}{ }_{4} \mathrm{OS}$ & 446.951 & 0.62 & 3.67 \\
\hline 2 & $\stackrel{p-}{\mathrm{ClC}_{6} \mathrm{H}_{4}}$ & $\begin{array}{l}\mathrm{p}-\mathrm{OCH}_{3} \mathrm{C}_{6} \mathrm{H}_{4} \\
\mathrm{C}_{\mathrm{A}}\end{array}$ & 39 & 202 & $\mathrm{C}_{25} \mathrm{H}_{21} \mathrm{ClN}_{4} \mathrm{O}_{2} \mathrm{~S}$ & 476.97784 & 0.68 & 3.77 \\
\hline 3 & $\begin{array}{l}p- \\
\mathrm{ClC}_{6} \mathrm{H}_{4}\end{array}$ & $\mathrm{p}-\mathrm{CH}_{3} \mathrm{C}_{6} \mathrm{H}_{4}$ & 53 & 210 & $\mathrm{C}_{25} \mathrm{H}_{21} \mathrm{CIN}_{4} \mathrm{OS}$ & 460.97844 & 0.73 & 4.11 \\
\hline 4 & $\begin{array}{l}p- \\
\mathrm{ClC}_{6} \mathrm{H}_{4}\end{array}$ & $\mathrm{p}-\mathrm{ClC}_{6} \mathrm{H}_{4}$ & 45 & 225 & $\mathrm{C}_{24} \mathrm{H}_{18} \mathrm{Cl}_{2} \mathrm{~N}_{4} \mathrm{OS}$ & $\begin{array}{l}\text { Formula Weight = } \\
481.39692\end{array}$ & 0.81 & 4.33 \\
\hline 5 & $\begin{array}{l}p- \\
\mathrm{ClC}_{6} \mathrm{H}_{4}\end{array}$ & m- $\mathrm{ClC}_{6} \mathrm{H}_{4}$ & 40 & 224 & $\mathrm{C}_{24} \mathrm{H}_{18} \mathrm{Cl}_{2} \mathrm{~N}_{4} \mathrm{OS}$ & 481.39692 & 0.80 & 4.33 \\
\hline 6 & $\begin{array}{l}p- \\
\mathrm{ClC}_{6} \mathrm{H}_{4}\end{array}$ & $\mathrm{CH}=\mathrm{CHC}_{6} \mathrm{H}_{4}$ & 31 & 209 & $\mathrm{C}_{26} \mathrm{H}_{21} \mathrm{ClN}_{4} \mathrm{OS}$ & 472.98914 & 0.56 & 3.82 \\
\hline 7 & $\begin{array}{l}m- \\
\mathrm{ClC}_{6} \mathrm{H}_{4} \\
\end{array}$ & $-\mathrm{C}_{6} \mathrm{H}_{5}$ & 36 & 237 & $\mathrm{C}_{24} \mathrm{H}_{17} \mathrm{ClN}{ }_{4} \mathrm{OS}$ & 446.951 & 0.67 & 3.51 \\
\hline 8 & $\begin{array}{l}m- \\
\mathrm{ClC}_{6} \mathrm{H}_{4} \\
\end{array}$ & $\mathrm{p}-\mathrm{OCH}_{3} \mathrm{C}_{6} \mathrm{H}_{4}$ & 31 & 229 & $\mathrm{C}_{25} \mathrm{H}_{21} \mathrm{ClN}_{4} \mathrm{O}_{2} \mathrm{~S}$ & 476.97784 & 0.61 & 3.69 \\
\hline 9 & $\begin{array}{l}m- \\
\mathrm{ClC}_{6} \mathrm{H}_{4} \\
\end{array}$ & $\mathrm{p}-\mathrm{CH}_{3} \mathrm{C}_{6} \mathrm{H}_{4}$ & 34 & 226 & $\mathrm{C}_{25} \mathrm{H}_{21} \mathrm{ClN}_{4} \mathrm{OS}$ & 460.97844 & 0.60 & 4.08 \\
\hline
\end{tabular}

